\title{
Determination of Kaduna Refining and Petrochemicals Company Limited (KRPC) Safety and Cost Reduction Models
}

\author{
${ }^{1}$ M.O. Oladejo and ${ }^{2}$ M.O. Macauley \\ ${ }^{I}$ Dept. of Mathematics Nigerian Defence Academy (NDA) Kaduna Kaduna State Nigeria \\ ${ }^{2}$ Dept. of HSE, Kaduna Refinery and Petrochemical Company (KRPC), Kaduna
}

\begin{abstract}
In this thesis we consider four multivariate models (i.e. three multiple regression models respectively) that captures the forecast mechanism of yearly total observation (YTO) of Man-Hour Worked for accident, man-hour lost for cost reduction, maintenance trend and Cost Reduction Linear Programming (LP) Model at the Kaduna Refining and Petrochemical Company (KRPC). Data were collected from Health, Safety and Environment Department (HSED), Planning Budget and Monitoring Department (PBMD) of KRPC records and classified into purposeful and logical categories for analysis. Multiple regression model was adopted as the suitable model for predicting the yearly total observation of man-hour worked as a result of accident in the system, man-hour lost as a result of accident which will assist the management in putting resources in place that will reduce cost in the system and maintenance models that will inform progressive routine maintenance plan in the system.
\end{abstract}

Keywords: KRPC, Safety, Accident, Maintenance, Man-hour Loss, Man-hour worked, Fire incident, Oil spillage, work permit.

\section{Introduction}

The decision to construct the third refinery in Kaduna was taken in 1974 along with that of the second NNPC refinery located at Warri. However, it was decided that work would commence on the construction of the third whenever the projection of the consumption of petroleum products justified it.

By early 1977 in view of the fuel shortages experienced then, the federal government decided that work on the third refinery should be advanced. It was envisaged that the refinery was to be a hydroskimming type refinery in order to meet up with fuel demand then.

Based on the feasibility studies carried out which took into consideration the consumption of the various petroleum products within the Northern zone, and adequate means of disposal for the surplus products, a crude oil capacity of 42,000 barrels per day (BPD) could be easily justified. Hence the refinery was designed for a capacity of 60,000 BPSD.

It was much later that the Federal government decided that the capacity for any refinery in Nigerian should not be below 100,000 BPD.

However, this would have led to the production of large quantity of heavy ends and on one practical and viable solution is reprocessing the heavy fuel oils in order to do this, the whole project plan had to be modified so that what initially was planned to be a simple hydroskimming type refinery developed into an integrated refinery. The refinery would now be able to produce a wider variety of petroleum products, some of which should be lubricating base oil. Hence it became necessary to import suitable paraffinic based crude oil from Venezuela, Kuwait or Saudi Arabia.

Products from refinery are to include fuels using such as liquidified petroleum gas (LPG), petrol, Automotive gas oil (AGO), kerosene, fuel oil and sulpur, and those from the lubricating oils complex are base oils, Asphalt and waxes.

The lubricating oil complex of KRPC is the first of its kind in West Africa and one of the largest in Africa.

The consulting firm, KING WILKINSON of Hague, Holland in conjunction with NNPC engineers developed the plan for the refinery. The contract for the construction was awarded to CHIYODA CHEMICAL ENGINEERING AND CONSTRUCTION COMPANY OF YOKOHAMA, JAPAN in 1977.

The project was completed and commissioned in 1980. However, the lubes plant and petrochemical plant were commissioned in 1983 and 1988 respectively. The initial operation and maintenance carried out by Nigerian Staff and expatriate personnel as technical backup.

By 1985, Nigerian staff had virtually taken over all the maintenance and operations.

For the past three (3) years there had been an increase in accident(s) cases leading to plant and equipment breakdown.

This fragment plant failure and industrial accidents have militated against high productivity and also affecting the company budget, planning negatively consequent to lack of forecast mechanism in place to capture the 
negative effect of accident(s) in the system (both to staff/equipment) with respect to man-hour worked/lost and lack of progressive maintenance in place in KRPC.

As part of the contribution to the way forward, there is the need in solving the problems of poor planning/budgeting/maintenance in KRPC, which may assist in curbing the challenges of petroleum products need in the Northern part of the country and also reducing the problem of importation of petroleum products into the country. This study is out to empirically provide model that will assist in forecasting man-hour worked, man-hour lost and maintenance trend. In KRPC, all these will assist in checking/reducing cost in the system in order to boost productivity in KRPC and hydro carbon industry in Nigeria that optimizes current level of compliance to safety audit in KRPC.

The rest of the paper is structured as follows: Section two (2) provides interactive review and theoretical framework for the study while section three (3) is on the methodology. Section four (4) focuses on results and discussion and the last section concludes the paper.

AIM:

To derive models for forecasting Man-hour worked, Man-hour loss and Maintenance schedule.

SCOPE: 1996-2009.

The study covers maintenance trend, safety audit and accident rate/prevention in KRPC operation from

Study area: The study was conducted in the Northern part of the country in Pardama Jarki-Rido village in the Southern part of the Kaduna state in Chikun Local Government Area where the third refinery of the country is sited. It is clear that the setting of the refinery in Kaduna had also contributed to providing employment to not less than 1500 Nigerians a means of livelihood to local entrepreneurs by awarding them petty contract jobs, on the whole, the impact of Kaduna refinery to the people of Kaduna state and other part of Northern states is very significant.

\section{STATEMENT OF THE PROBLEM}

For the past three (3) years there had been an increase in accident(s) cases leading to plant and equipment breakdown. This fragment plant failure and industrial accidents have militated against high productivity. Safety audit of plant and equipments are carried out twice a year in KRPC to determine their operational status.

The safety audit is also to check any possible deviation and to ensure uninterrupted operations and accident prevention. Non compliance to the recommendations made is now the major challenges that inform this study.

\section{OBJECTIVES OF THE STUDY}

1. To collate and tabulate records from KRPC.

2. To derive mathematical models required using Statistical Package for the Social Science (SPSS) and Excel Solver.

3. Use derived models for forecasting.

4. Analyse results.

\section{SIGNIFICANCE OF THE STUDY}

The refinery also contributed it quota in the field of technological transfer by providing ensuring students from Polytechnics, Monotechnics, Universities and other institutions of higher learning with relevant industrial work experience. The refinery was also used to train and develop local staff in the field of petroleum refinery technology that saw to the phasing out of hired foreign expatriate and consultants.

The exposure of the staff of the refinery put them at the forefront of developing our petroleum industries today in the country.

Management performance enhancement, prompt handling of technical problems and cost savings.

\section{Literature Review And Theoretical Framework}

The first analysis of industrial accident causation and prevention started with Heinrich (1931) who affirmed that $88 \%$ of accidents are caused by "unsafe acts of person" and put forth what often is referred to as Heinrich accident triangle or pyramid. In a group of 330 accidents result on minor injuries, result on minor injuries, 29 will result on minor injuries and 1 will result on a major accident. His famous theories on industrial accidents include unsafe acts of persons are responsible for mort accidents and the 300:29:1 ratio of work place accident. (Heinrich 1931) 
British safety council public (1972:13) James Staples equally states that $90 \%$ of all accidents are attributed to human behaviours. Taubitz (1980) question the Heinrich model. He and his colleagues noticed that the exposures causing fatalities had nothing to do with sprains, strains or other reportable injuries "and use intuitively understand the Heinrich model didn't fit because it cannot help to forecast severe accident and fatalities" he said and that Heinrich model is just a foundation for accident prevention. Taubitz (1980) therefore said each system will have to derive and adapt its own models.

However, over the years Heinrich's methodology though widely applied has been undergoing many refinement and improvement.

We shall also borrow leaf from the work of JAMES T. REASON (1990) a British psychologist of the University of Manchester propounded a model of accident causation termed SWISS MODEL. A model used in risk analysis and risk management of human systems commonly used in aviation engineering and health care. It likens human systems as to multiple stress of Swiss cheese stacked together, side by side. The system as a whole produces failure when all of the holes in each of the slices momentarily align, permitting (In Reason words) "a trajectory of accident opportunity" so that a hazard passes through all of the holes in all of the defences leading to a failure. Frosch (2001) describes Reason Model in mathematical terms as being a model in percolation theory which he analyses as a "Bethe lattice".

Lubnau, Okray (2004) apply Reason's Swiss model to the engineering of human systems in the field of fire fighting, with the aim of reducing human errors by "inserting additional layers of cheese in the system" namely the techniques of crew resources management. In this Swiss model individual weaknesses are model as holes in slices of Swiss cheese such as Emmental. They represent the imperfections in individual safeguards or defences which in the real world rarely approach the ideal of being completely proof against failure.

Crew Resource Management for the Fire Service, Pennwell Books pp. 20-21 ISBN 1593700067.

NNPC has Group Health Safety Policy Statement (2012) which states that NNPC is committed to conducting its activities in a manner that promotes the Health and safety of her Employees, Assets and public as well as the protection of the Environment.

This policy shall be of uniform application throughout the NNPC group in which KRC is in part.

KRPC has an accident prevent policy which recognizes that in the design stage of the process and manufacturing plants, appropriate design conditions effective control system and reliable construction materials have been selected on the basis of their suitable scientific relationship Abdulkadir, Aguba 2008:6 (chief officers MDP course 054) unpublished.

Yaya (2006:8 chief officers MDP course 052) unpublished propounded that: Ageing workforce, obsolete equipments, poor maintenance and lack of professionalism was responsible for increased frequent fire incidences in KRPC.

On this work we shall digress a little from their works but to describing in a mathematical terms how we can forecast the consequence of accidents in the system in relation to man-hour worked/loss and maintenance rate applying regression model; this will assist the management team of KRPC and other NNPC group in attaining accurate planning/budgeting and maintenance monitoring in the system that will lead to high production activities.

Therefore, a Cost Reduction (LP) Model shall be considered also on this work because safety depends on equipments and measures which require controlled finance.

Prediction or estimation is one of the major problems in almost all spheres of human activities. The prediction of future activities are important to businessman. Thus the statistical device which estimate or predict the unknown values of one variable from the known values of another variable is known as regression.

Pillai, Bagaiathi (2012) the regression line describes the average relationship existing between X and Y variable. Siegel (2002) stated that once $\mathrm{R}^{2}$ is greater than or equal to 0.60 or $60 \%$ the model is an accurate one and can be used for prediction or estimation.

The regression model which was independently proposed by Meyers (2002) is given thus:

$\hat{Y}_{i}:=\hat{\alpha}+\hat{b}_{1} x_{1}+\hat{b}_{2} x_{2}+b_{3} x_{3}+\cdots+\hat{b}_{k} x_{k}+\ell$

Where

$\widehat{Y}_{i}=$ estimated value of $\mathrm{Y}$ given a specific value of $\mathrm{X}$.

$\hat{\alpha}=$ estimate of the true intercept $b$

$\hat{b}_{1}=$ estimate of the true parameter bi

$\ell=$ estimate of the true random terms $\mu$

\section{Materials And Methods}

This involves derivations of the models using SPSS package and data from KRPC. 


\section{Types of data collected:}

The data used were secondary: the data were collected from the records of the Health Safety and Environment (HSED) and Planning Budget and Monitoring Department (PBMD) of the Management authorities of Kaduna Refinery and Petrochemical Company (KRPC).

\section{METHODS OF DERIVATION OF SOLUTION AND ANALYSIS:}

Methodology:

Tabulated data were fed into the computer package software SPSS and run several times. The values of the regression coefficients were obtained. These values of $(\beta)$ were used to express the models as required.

Table 1: Data on accident, man-hour worked and loss

\begin{tabular}{|l|l|l|l|l|l|l|l|}
\hline $\mathbf{W}$ & $\mathbf{X}_{\mathbf{1}}$ & $\mathbf{X}_{\mathbf{2}}$ & $\mathbf{X}_{\mathbf{3}}$ & $\mathbf{X}_{\mathbf{4}}$ & $\mathbf{X}_{\mathbf{5}}$ & $\mathbf{X}_{\mathbf{6}}$ & $\mathbf{X}_{\mathbf{7}}$ \\
\hline 1 & 28 & 1760 & 5 & 31 & 19 & 2265 & 3398066 \\
\hline 2 & 12 & 524 & 11 & 39 & 10 & 2111 & 3397542 \\
\hline 3 & 5 & 120 & 6 & 43 & 15 & 2823 & 3392442 \\
\hline 4 & 15 & 1112 & 20 & 34 & 15 & 2072 & 3391330 \\
\hline 5 & 9 & 268 & 9 & 24 & 16 & 2101 & 3392241 \\
\hline 6 & 7 & 248 & 7 & 36 & 15 & 2073 & 3392440 \\
\hline 7 & 5 & 168 & 7 & 23 & 32 & 2122 & 3392436 \\
\hline 8 & 3 & 232 & 6 & 32 & 18 & 2193 & 3299101 \\
\hline 9 & 6 & 520 & 0 & 13 & 10 & 2300 & 3299302 \\
\hline 10 & 3 & 96 & 6 & 25 & 11 & 2216 & 3299336 \\
\hline 11 & 0 & 0 & 1 & 6 & 14 & 2166 & 3299436 \\
\hline 12 & 5 & 264 & 1 & 9 & 10 & 2206 & 3299172 \\
\hline 13 & 2 & 56 & 2 & 0 & 12 & 2741 & 3299368 \\
\hline TOTAL & 3 & 96 & 7 & 0 & 7 & 2986 & 3299336 \\
\hline
\end{tabular}

Where:

$\begin{array}{lll}\mathrm{X}_{1} & = & \text { No of Accident (personnel) } \\ \mathrm{X}_{2} & = & \text { Man hour Loses (hrs) } \\ \mathrm{X}_{3} & = & \text { Property Damage Accident } \\ \mathrm{X}_{4} & = & \text { Fire Incidents (No. of cases) } \\ \mathrm{X}_{5} & = & \text { Oil Spills (No. of cases) } \\ \mathrm{X}_{6} & = & \text { Training of Personnel (No. of Personnel) } \\ \mathrm{X}_{7} & = & \text { Total Man-hour Worked }\end{array}$

i. Man Hour Worked Model with respect to accident. Table 1

$\hat{Y}_{i}:=\hat{\alpha}+\hat{\beta}_{1} \mathrm{X}_{1}+\hat{\beta}_{2} \mathrm{X}_{2}+\hat{\beta}_{3} \mathrm{X}_{3}+\cdots+\hat{\beta}_{6} \mathrm{X}_{6}$

Where:-

$\hat{Y}_{1}=$ Yearly total observation of man-hour worked for accident

$\mathrm{X}_{1}=\quad$ Yearly observation on numbers of accidents (personnel)

$\mathrm{X}_{2}=$ Yearly observation on man-hour loses (hrs)

$\mathrm{X}_{3}=$ Yearly observation on property damage accident

$\mathrm{X}_{4}=\quad$ Yearly observation on fire incidents (No. of cases)

$\mathrm{X}_{5}=$ Yearly observation on oil spills (No. of loses)

$\mathrm{X}_{6}=$ Yearly observation on training of personnel (No. of persons)

ii. Man-Hour Lost Model based on available data. Table 1

$\hat{Y}_{2}=\hat{\alpha}+\hat{\beta}_{1} \mathrm{X}_{1}+\hat{\beta}_{2} \mathrm{X}_{2}$

Where

$\widehat{Y}_{i}=$ Yearly total estimation of man-hour lost.

$\mathrm{X}_{1}=$ Year to year total Nos of accident to personnel/property. 
Table 2: Data used for Maintenance Model

\begin{tabular}{|c|c|c|c|c|c|}
\hline $\mathbf{Y}$ & $\mathbf{X}_{\mathbf{1}}$ & $\mathbf{X}_{\mathbf{2}}$ & $\mathbf{X}_{\mathbf{3}}$ & $\mathbf{X}_{\mathbf{4}}$ & $\mathbf{X}_{\mathbf{5}}$ \\
\hline 1 & 1320 & 181 & 1452 & 11 & 7 \\
\hline 2 & 1665 & 363 & 2112 & 19 & 5 \\
\hline 3 & 6483 & 3450 & 4608 & 33 & 2 \\
\hline 4 & 1935 & 1771 & 2376 & 37 & 0 \\
\hline 5 & 3019 & 2112 & 2641 & 36 & 0 \\
\hline 6 & 3014 & 2160 & 2905 & 43 & 0 \\
\hline 7 & 3432 & 2279 & 3168 & 49 & 0 \\
\hline 8 & 5472 & 2277 & 3432 & 40 & 1 \\
\hline 9 & 6003 & 2904 & 3269 & 46 & 0 \\
\hline 10 & 6063 & 2530 & 3300 & 87 & 2 \\
\hline 11 & 6103 & 2662 & 4140 & 97 & 3 \\
\hline 12 & 6206 & 3872 & 3696 & 123 & 0 \\
\hline 13 & 6758 & 5223 & 6600 & 166 & 21 \\
\hline Total & 4752 & 1593 & 4140 & 102 & 889 \\
\hline
\end{tabular}

$\mathrm{X}_{1}=$ Hot work permit (HWP) Total: year by year.

$\mathrm{X}_{2} \quad=\quad$ Vessel Entry Permit (VEP) Total: year by year.

$\mathrm{X}_{3} \quad=\quad$ Cold Work Permit (CWP) Total: year by year.

$\mathrm{X}_{4}=\quad$ Excavation Work Permit (EWP) Total: year by year.

$\mathrm{X}_{5} \quad=\quad$ Acid Area Work Permit (AAWP) Total: year by year.

$\mathrm{X}_{\mathrm{T}} \quad=\quad$ Period under review

iii. Maintenance Model based on available data. Table 2

$\hat{Y}_{3}=\hat{\alpha}+\hat{\beta}_{1} X_{1}+\hat{\beta}_{2} X_{2}+\hat{\beta}_{3} X_{3}+\hat{\beta}_{4} X_{4}+\hat{\beta}_{5} X_{5}$

$\hat{Y}_{i}=$ Yearly total observation of VEP

$\mathrm{X}_{1}=$ Yearly observation of Hot Work Permit (HWP) year by year total

$\mathrm{X}_{2}=$ Yearly observation of Cold Work Permit (CWP) year by year

$\mathrm{X}_{3}=$ Yearly observation of Excavation Work Permit (EWP) year by year total

$\mathrm{X}_{4}=$ Yearly observation of Acid Area Work Permit (AAWP) year by year

$\mathrm{X}_{5} \stackrel{\text { total }}{=}$ Period under review.

The $\alpha$ and $\beta$ coefficients are unknown parameters to be estimated along with the $x_{i}=(\mathrm{i}=1,2, \ldots)$ independent regressors

The parameters of the models were obtained through estimation method using the computer software programme; statistical package for social science (SPSS).

Table 3: Data used for Cost Reduction (LP) Linear Model

$\underline{\text { NNPC }(\text { CAS })}$

(OPERATION: STAFF ONLY) AS AT 2011

\begin{tabular}{|c|c|c|c|c|c|c|c|}
\hline GRADE LEVEL & \multicolumn{2}{|c|}{$\begin{array}{l}\text { CONSOLIDATED } \\
\text { ANNUAL SALARY } \\
\text { SCALE }\end{array}$} & \multicolumn{2}{|c|}{$\begin{array}{c}\text { NO. OF } \\
\text { PERSONNEL }\end{array}$} & $\begin{array}{l}\text { GROUP } \\
\text { TOTAL }\end{array}$ & $\begin{array}{l}\text { GROUP } \\
\text { AVERAGE }\end{array}$ & REMARKS \\
\hline \multirow{2}{*}{ DMS AND ABOVE } & RANGE & $\bar{x}$ & $\mathrm{~N}$ & Total $(\mathrm{n} \mathbf{x})$ & \multirow{3}{*}{$4641.5 \mathrm{~m}$} & \multirow{3}{*}{$12.93 \mathrm{~m}$} & \multirow{2}{*}{$\begin{array}{l}\text { TOP } \\
\text { MANAGEMENT } \\
\text { OFFICERS }\end{array}$} \\
\hline & $18.0 \mathrm{~m}-24.0 \mathrm{~m}$ & $21 \mathrm{~m}$ & 54 & $1134 \mathrm{~m}$ & & & \\
\hline SS1 (CHIEF OFFICERS) & $9.0 \mathrm{~m}-14.0 \mathrm{~m}$ & $11.5 \mathrm{~m}$ & 305 & $3507.5 \mathrm{~m}$ & & & EXPERTS \\
\hline SS3 - SS2 & $8.0 \mathrm{~m}-12.0 \mathrm{~m}$ & $10.0 \mathrm{~m}$ & 200 & $2000 \mathrm{~m}$ & & & TECHNICIANS \\
\hline SS7 - SS4 & $6.0 \mathrm{~m}-8.0 \mathrm{~m}$ & $7.0 \mathrm{~m}$ & 300 & $2100 \mathrm{~m}$ & $4100 \mathrm{~m}$ & $8.2 \mathrm{~m}$ & TECHNICIANS \\
\hline $\begin{array}{l}\text { JSS4 - JSS1 AND } \\
\text { GRADUATE } \\
\text { TRAINEES }\end{array}$ & $1.2 \mathrm{~m}-3.6 \mathrm{~m}$ & $2.4 \mathrm{~m}$ & 540 & $1296 \mathrm{~m}$ & $1296 \mathrm{~m}$ & $2.4 \mathrm{~m}$ & $\begin{array}{l}\text { GRADUATE } \\
\text { TRAINEES } \\
\text { AND OTHERS }\end{array}$ \\
\hline TOTAL NO. OF STAFF & & & 1,399 & & & & \\
\hline
\end{tabular}

Remarks: 
GTS and others $\quad=540$

Total nos. of personnel $\underline{\underline{1,399}}$

iv. Cost Reduction (LP) Model

$$
\begin{aligned}
& \min \mathbf{w}=c_{1} x_{1}+c_{2} x_{2}+c_{3} x_{3} \quad \geq b_{1} \\
& \text { Sjt: } \quad a_{11} x_{1}+a_{12} x_{2}+a_{13} x_{3} \geq b_{2} \\
& a_{21} x_{1}+a_{22} x_{2}+a_{23} x_{3} \geq b_{3} \\
& a_{31} x_{1}+a_{32} x_{2}+a_{33} x_{3} \\
& x_{1}, x_{2}, x_{3}, \geq 0
\end{aligned}
$$

From NNPC CAS table: $\left(c_{1}, c_{2}, c_{3},\right)=(12.93,8.30,2.40)$

(See Appendix 21)

$$
\begin{aligned}
& x_{1}=359 \\
& x_{2}=500 \\
& x_{3}=540 \\
& c_{1}=12.93 \\
& c_{2}=8.30 \\
& c_{3}=2.40
\end{aligned}
$$

$$
\begin{gathered}
\left(\begin{array}{l}
b_{1} \\
b_{2} \\
b_{3}
\end{array}\right)=\left(\begin{array}{l}
4.64905 \\
4.10010 \\
1.29600
\end{array}\right) \\
x_{1} \geq 359 \\
x_{2} \geq 500 \\
x_{3} \geq 540
\end{gathered}
$$

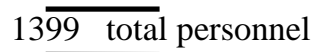

$$
A=\left(\begin{array}{ccc}
89.65 & 17.7 & 39.5 \\
36.8 & 29.5 & 19.9 \\
59.9 & 58.7 & 66.3
\end{array}\right)
$$

Using Excel Solver (page 56-59 of Operation Research an Introduction $8^{\text {th }}$ Edition by Hamdy A. Taha) after feeding necessary data, results were obtained.

\section{Results}

Table 3: Summary of models result

\begin{tabular}{|l|l|l|l|l|l|l|l|}
\hline Model & $\mathbf{R}^{2}$ & $\begin{array}{l}\text { Prob. } \\
\text { Level }\end{array}$ & F-ratio & $\begin{array}{l}\text { Power } \\
\text { test }\end{array}$ & Durbin-watson & AAPE & CAAPE \\
\hline $\begin{array}{l}\text { Man-hour worked } \\
\text { for accident model } \\
(1)\end{array}$ & 0.8349 & 0.0172 & 5.899 & 0.8582 & 1.320662135 & 0.481 & $0.000015 \%$ \\
\hline $\begin{array}{l}\text { Maintenance model } \\
(2)\end{array}$ & 0.8852 & 0.0014 & 12.341 & 0.9958 & 2.06164561 & 26.548 & $1.11 \%$ \\
\hline $\begin{array}{l}\text { Man-hour lost for } \\
\text { cost reduction } \\
\text { model (3) }\end{array}$ & 0.9410 & 0.0000 & 87.761 & 1.0000 & 1.984312607 & 38.493 & $9.86 \%$ \\
\hline
\end{tabular}

Table 4: Cost Reduction (LP) Model Result Using Excel Solver: Based on table 3

\begin{tabular}{|l|l|l|l|}
\hline Global optimal solutions found & & & \\
\hline Objective value & & 49448.44 & \\
\hline Infeasibilities & & 0.000000 & \\
\hline Total solver iterations & & 1 & \\
\hline Model class: & & LP & \\
\hline Total variables: & 3 & & \\
\hline Nonlinear variables & 0 & & \\
\hline Integer variables & 0 & & \\
\hline Total constraints & 7 & & \\
\hline Nonlinear constraints & 0 & & \\
\hline Total nonzero & 15 & & Reduced cost \\
\hline Nonlinear nonzero & 0 & & 8.491809 \\
\hline & Variable & Value & 4.742211 \\
\hline & X1 & 0.000000 & \\
\hline
\end{tabular}




\begin{tabular}{|l|l|l|l|}
\hline & $\mathrm{X} 3$ & 20603.52 & 0.000000 \\
\hline & & & \\
\hline & Row & Slack or surplus & Dual price \\
\hline & 1 & 49448.44 & -1.000000 \\
\hline & 2 & 348933.9 & 0.000000 \\
\hline & 3 & 0.000000 & -0.1206030 \\
\hline & 4 & 1236413. & 0.000000 \\
\hline & 5 & 0.000000 & 0.000000 \\
\hline & 6 & 0.000000 & 0.000000 \\
\hline
\end{tabular}

Actual safety cost

Optimal high cost -

N23.446bn

N49.448bn

Optimal Solution

$$
\begin{aligned}
& x_{1}=0 \\
& x_{2}=0 \\
& x_{3}=2060.4
\end{aligned}
$$

This is optimal model solution but in reality, this is not true or feasible, because $x_{1}=0, x_{2}=0$.

However, in reality:

$$
\begin{array}{lc}
x_{1}=359 & (\text { Experts }) \\
x_{2}=500 & (\text { Technicians }) \\
x_{3}=540 & \text { (Trainees) }
\end{array}
$$

There is the need to conduct a thorough research to determine accurate values that would be required to obtain optimal solutions. This procedure would involve investigation.

The derived models are as follows:

1. Man-Hour Worked Model:

$\hat{Y}_{1}=3455783.8463-27.5042 \mathrm{X}_{1}+270.3397 \mathrm{X}_{2}-1032.3357 \mathrm{X}_{3}+1335.9143 \mathrm{X}_{4}+5.8721 \mathrm{X}_{5}$ $-14439.0721 \mathrm{X}_{6}$

Table 4: Actual and Predicted values for Man-Hour Worked Model

Actual

C7

3402174.000

3400249.000

3395454.000

3394598.000

3394668.000

3394826.000

3394793.000

3301585.000

3302151.000

3301693.000

3301623.000

3301667.000

3302181.000

3299336.000
Predicted

C7

3414486.467

3400961.402

3403013.522

3369956.087

3387586.377

3359268.347

3383448.252

3339401.674

3324974.740

3312274.108

3322452.253

3292546.297

3296854.025

3279774.449 


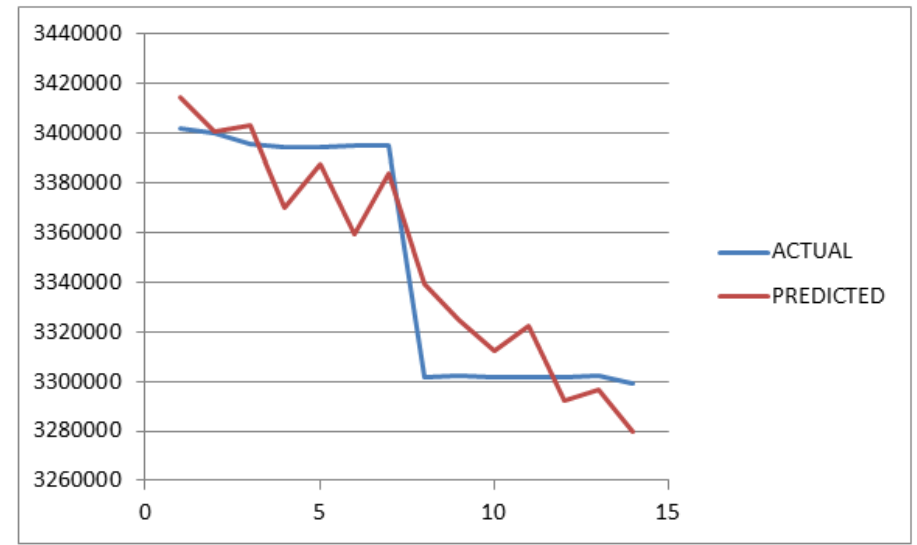

Plot of Actual and Predicted value of accident (man-hour worked) Fig. 1

2. Maintenance Model

$\hat{Y}_{2}=683.2055+0.3868 \mathrm{X}_{1}+0.1723 \mathrm{X}_{2}+26.5234 \mathrm{X}_{3}-160.684 \mathrm{X}_{4}-269.725 \mathrm{X}_{5}$

Table 5: Actual and Predicted values for Maintenance Model

$\begin{array}{rrr}\text { Row } & \text { Actual } & \text { Predicted } \\ 1 & \mathbf{C 2} & \mathbf{C 2} \\ 2 & 181 & 75.97 \\ 2 & 363 & 852.193 \\ 3 & 3450 & 3768.247 \\ 4 & 1771 & 1743.508 \\ 5 & 2112 & 1912.229 \\ 6 & 2160 & 1871.715 \\ 7 & 2279 & 1972 \\ 8 & 2277 & 2133.609 \\ 9 & 2904 & 2200.345 \\ 10 & 2530 & 3046.631 \\ 11 & 2662 & 3363.012 \\ 12 & 3872 & 3424.879 \\ 13 & 5223 & 4848.804 \\ 14 & 1593 & 2163.858\end{array}$

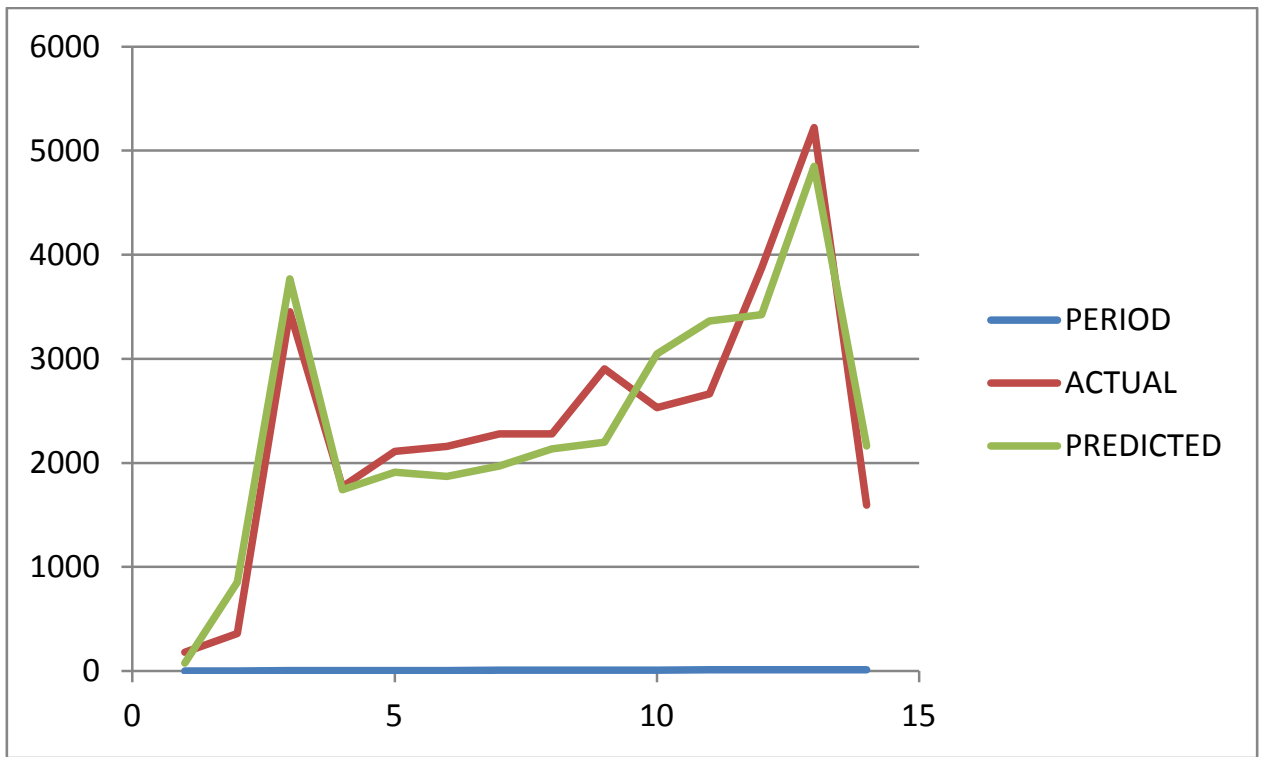

Plot of Actual and Predicted value for maintenance fig. 2 
3. Man-Hour Lost Model

$\hat{Y}_{3}=1227.7165+68.4422 \mathrm{X}_{1}-0.0004 \mathrm{X}_{2}$

Table 6: Actual and Predicted values for Man-Hour Lost Model

$\begin{array}{lrr}\text { Row } & \begin{array}{r}\text { Actual } \\ \text { C2 }\end{array} & \begin{array}{r}\text { Predicted } \\ \text { C2 }\end{array} \\ 1 & 1760.000 & 1799.131 \\ 2 & 524.000 & 474.697 \\ 3 & 120.000 & 227.194 \\ 4 & 1112.000 & 912.048 \\ 5 & 268.000 & 501.035 \\ 6 & 248.000 & 364.071 \\ 7 & 168.000 & 227.189 \\ 8 & 232.000 & 127.247 \\ 9 & 520.000 & 332.494 \\ 10 & 96.000 & 127.153 \\ 11 & 0.000 & -78.213 \\ 12 & 264.000 & 264.103 \\ 13 & 56.000 & 58.699 \\ 14 & 96.000 & 127.153\end{array}$

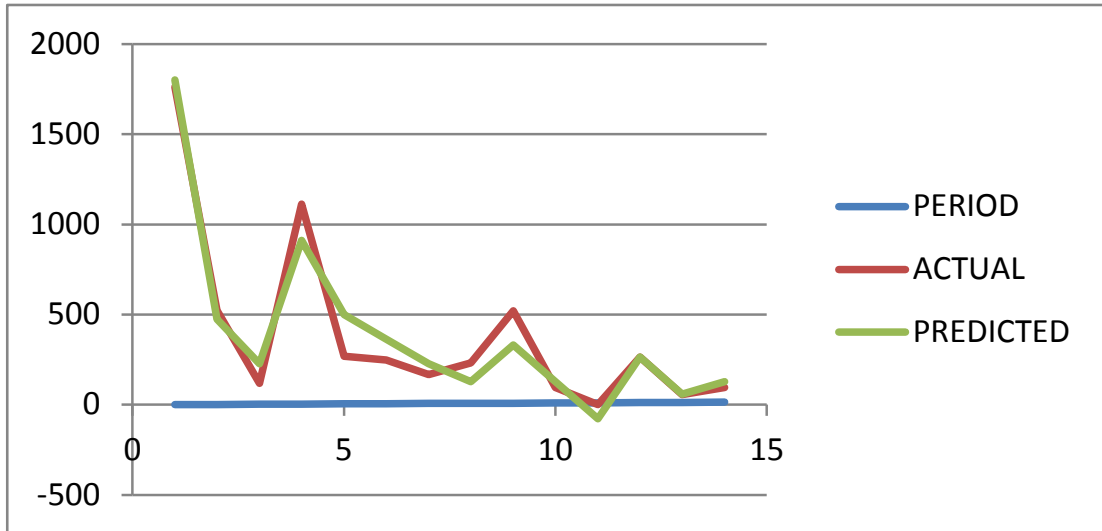

Plot of actual and predicted value of man-hour lost for cost reduction model. Fig. 3

\section{Cost Reduction Linear Programming (LP) Model}

Cost Reduction (LP) Model Result Using Excel Solver

\begin{tabular}{|c|c|c|c|}
\hline Global optimal solutions found & & & \\
\hline Objective value & & 49448.44 & \\
\hline Infeasibilities & & 0.000000 & \\
\hline Total solver iterations & & 1 & \\
\hline Model class: & & LP & \\
\hline Total variables: & 3 & & \\
\hline Nonlinear variables & 0 & & \\
\hline Integer variables & 0 & & \\
\hline Total constraints & 7 & & \\
\hline Nonlinear constraints & 0 & & \\
\hline Total nonzero & 15 & & \\
\hline Nonlinear nonzero & 0 & & \\
\hline & Variable & Value & Reduced cost \\
\hline & $\mathrm{X} 1$ & 0.000000 & 8.491809 \\
\hline & $\mathrm{X} 2$ & 0.000000 & 4.742211 \\
\hline & $\mathrm{X} 3$ & 20603.52 & 0.000000 \\
\hline & Row & Slack or surplus & Dual price \\
\hline & 1 & 49448.44 & -1.000000 \\
\hline & 2 & 348933.9 & 0.000000 \\
\hline & 3 & 0.000000 & -0.1206030 \\
\hline & 4 & 1236413. & 0.000000 \\
\hline & 5 & 0.000000 & 0.000000 \\
\hline & 6 & 0.000000 & 0.000000 \\
\hline & 7 & 20603.52 & 0.000000 \\
\hline
\end{tabular}


Actual safety cost Optimal high cost -

Optimal Solution

\section{N23.446bn}

\section{N49.448bn}

$$
\begin{aligned}
& x_{1}=0 \\
& x_{2}=0 \\
& x_{3}=2060.4
\end{aligned}
$$

This is optimal model solution but in reality, this is not true or feasible, because $x_{1}=0, x_{2}=0$.

However, in reality:

$$
\begin{array}{lc}
x_{1}=359 & (\text { Experts }) \\
x_{2}=500 & (\text { Technicians }) \\
x_{3}=540 & (\text { Trainees })
\end{array}
$$

There is the need to conduct a thorough research to determine accurate values that would be required to obtain optimal solutions. This procedure would involve investigation.

\section{Discussion}

From the above analysis of variance the models it is established and evidently clear that the three models developed for the determination of man-hour worked w.r.t accident model, maintenance level activities and man-hour lost w.r.t cost reduction model have good prediction power and therefore good for predicting their respective purposes.

The research work has achieved its main objectives among others four (4) multivariate models was objectively built respectively (i.e. (i) Man-hour worked for Accident model (ii) Maintenance model (iii) Manhour lost for Cost reduction model (iv) Cost Reduction (LP) Model which were empirically compared to ascertain their prediction powers and all found capable of predicting their inherent purpose.

On a general research note, however, other relevant research issues were isolated to give a broad spectrum of understanding of the research objectives and how they were fully achieved. These relevant research issues were set to choose a more robust model for predicting safety models that enhance productivity in Kaduna Refining and Petrochemical Company Limited (KRPC LTD) among others.

Moreover, in order to achieve the research objectives, some relevant and related literature were duly consulted and cited herein. The consultations of the related literatures have really acquainted the researcher of the work done so far and how he could plan for the study in order to achieve his research objectives with ease.

In a nutshell, the works of Heinrich, H.W. et al (1931) Dupont, et al (1950), Sunil, S.R. et al (2004), James T. Reason (1990), Lubnau and Okray (2004), Abdulkadir and Aguba (2006), Yaya (2006), Colin Chen, et al (2011), Siegel (2002), Meyers (2002), among others, were reviewed and mainstreamed into the study.

Furthermore, the detailed methodology for the study was clearly outlined. Data were collected through documentary method with a sample size of $14 \mathrm{yrs}$. The relevant data were collected and objectively analysed using multiple regression analysis.

The data collected and used for the study were initially displayed on a table for easy access and to facilitate analysis.

The data was divided into two parts. One part was used to build the models while the other part was used to ascertain empirically their respective prediction accuracy of the various models.

The data analysis was conducted objectively and in factual manner using the tables.

Therefore, the multiple regression models built was as follows:

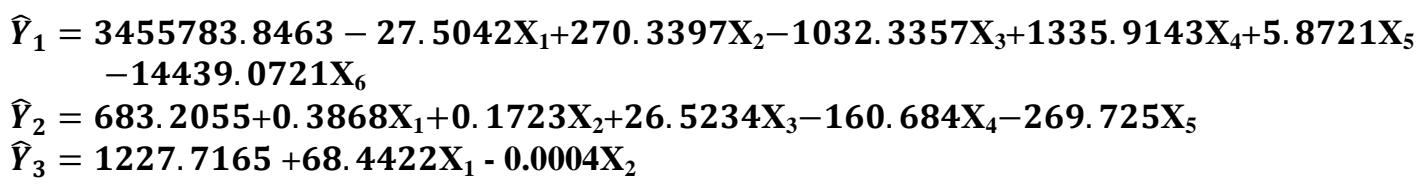


Moreover, this method has satisfied all the validation and diagnostic test of goodness of fit, autocorrelation, homoscedascicity and multicollinearity. Consequently, the models was used to predict the yearly total observation of man-hour worked for accident, maintenance and man-hour lost for cost reduction mechanism in the system.

It is therefore, very important to critically examine each of the models with a view to understanding the extent of applicability of the models. This critical examination will enable us to have a detailed analysis of the models so as to explore the advantage or otherwise their prediction powers in term of goodness of fit or probability of miscalculation.

1. The multiple regression model for man-hour worked for accident model with six predictor variables has a coefficient of determination of $R^{2}=0.8349$ or simply $83.49 \%$.

This implies that the six predictor variables included in the model can explain at least $83.49 \%$ of change in the yearly total observation of man-hour worked which is good enough for the model.

In the test run, the model has predicted the yearly total observation of man-hour worked w.r.t accident for fourteen (14) years whose actual yearly total observation were already known with an Average Absolute Percent Error (AAPE) of 0.481. To express it in another form, using Coefficient of Average

Absolute Percent Error (CAAPE), with the value of $0.000015 \%$, implies that the model can predict yearly total observation of man-hour worked w.r.t accident in the system.

The model prediction power was very good with $\mathrm{R}^{2}$ of 0.8349 , Probability level of 0.0172 , F-ratio of 5.899, Power test of 0.8582 and Durbin-watson of 1.320662135 . This implies that the model can predict total observation of man-hour worked with a CAAPE of only $0.000015 \%$ on the average.

2. The multiple regression model of Vessel Entry Permit (VEP) for maintenance with five predictor variables has a coefficient of determination of $R^{2}=0.8852$ or simply $88.52 \%$.

This implies that the five predictor variables included in the model can explain at least $88.52 \%$ of change in the yearly total observation of Vessel Entry permit (VEP) for maintenance activities which is good enough for the model.

In the test run, the model has predicted the yearly total observation of maintenance activities for fourteen (14) years, whose actual yearly total observation were already known with an Average Absolute Percent Error (AAPE) of 26.548.

To express it in another form, using the Coefficient of Average Absolute Percent Error (CAAPE), with value of $1.11 \%$, implies that the model can predict yearly total observation of Vessel Entry Permit (VEP) for maintenance activities.

The model prediction power is very good with $\mathrm{R}^{2}$ of 0.8852 , Probability level of 0.0014 , F.Ratio of 12.341 , Power test of 0.9958 and Durbin-Watson of 2.06164561. This implies that the model can predict total observation of Vessel Entry Permit (VEP) for maintenance activities with a CAAPE of only $1.11 \%$ on the average.

3. The cost reduction model as a template for reducing cost of operation in dwindling budgetary allocation in the system with two (2) predictor variables has a coefficient of determination of $R^{2}=0.9410$ or simply $94.1 \%$.

This implies the two predictor variables included in the model can explain at least $94.1 \%$ of change in the yearly total observation of man-hour lost for cost reduction which is good enough for the model.

In the test run, the model has predicted the yearly total observation of man-hour lost for fourteen (14) years, whose actual yearly total observation were already known with an Average Absolute Percent Error (AAPE) of 38.493. To express it in another form, using the Coefficient of Average Absolute Percent Error (CAAPE), with value of $9.86 \%$, implies that the model can predict yearly total observation of man-hour lost in the production operation. 
The model prediction power is very good with $\mathrm{R}^{2}$ of 0.9410 , Probability level of 0.0000, F.Ratio of 87.761, Power test of 1.0000 and Durbin-Watson of 1.98431261. This implies that the model can predict total observation of man-hour lost for cost reduction in the production operation with a CAAPE of only $9.86 \%$ on the average.

From the available values of the three (3) models, Average Absolute Percent Error (AAPE), Coefficient of Average Absolute Percent Error (CAAPE) and graph of forecast of the models, it is evidently clear that the multiple regression model has high prediction power.

4. Global optimal solutions found considering the model result obtained through the Excel solver. (See table 4)

\section{Conclusion}

Objectively, this study has applied to all the laid down procedure to collect, analyse and interpret safety data for the purpose of evaluating the trend of accidents and maintenance in the system.

The outcome of the analysis has produced four (4) separate mathematical models each capable of independently predicting yearly total nos. of man-hour worked as a result of accident, maintenance and manhour lost for cost reduction.

Conclusively, the multiple regression models should be used for predicting yearly total observation of man-hour worked resulting from accident, maintenance activities and man-hour lost for cost reduction mechanism in the system.

\section{References}

[1]. $\quad$ Abdulkadir, Bara-Hart (2008:6): “Work Permit and Accident Rate in KRPC Plant Operations". NNPC Chief Officers MDP Course 055 (Unpublished)

[2]. Aguba, Peterson (2006): "Work Permit System and Accident Prevention" NNPC Chief Officers MDP Course 054 (Unpublished). PP.9

[3]. Aguba, James (2006): "Safety Audit Compliance and Accident Prevention in KRPC" ABB Lumus Survey Report. NNPC Chief Officers MDP Course 054 (Unpublished). PP. 8

[4]. Dan H. Barber and Robert E. Donovan (2004): Industry Safety Engineering and Management Hand Book. Zub-Chord Publishers.

[5]. Dupont (1950): A world Leader in Industrial Safety Management "Causes of Industrial Accident" www.dupont.com/safety1 (1950)

[6]. Grey Simon (2003): Multiple Regression Basics. New York University, Stern School of Business

[7]. Hamdy A. Taha (2004): "Operation Research. An Introduction. $8^{\text {th }}$ Edition

[8]. Hamdy A. Taha (2009): “Operation Research. An Introduction. $9^{\text {th }}$ Edition

[9]. Hayhurst, E.R. (January 1932): Review of Industrial Accident Prevention: A scientific approach. AMJ Public Health Nations Health 22(1): 119-20

[10]. Heinrich, HW (1931): Industrial accident prevention: a scientific approach. McGraw-Hill. ISBN 0-256-01564-3

[11]. Ikhagbode (2010): "Accident Prevention and Industrial Safety in KRPC". NNPC Chief Officers MDP Course 055 (Unpublished). PP. 8

[12]. John Fox (2008): Applied Regression Analysis and Generalised Linear model $2^{\text {nd }}$ Edition

[13]. KRPC LTD (2002-2003): Work Permit System: Annual Fires, Safety and Environment Report.

[14]. Lubnau, Okray (2004): Crew resource management for the fire service. Pennwell books pp.20-21 ISBN 1593700067

[15]. Peterson (1981): "Accident Prevention in the Downstream Sector". NNPC Chief Officers MDP Course 037 (Unpublished). PP. 45

[16]. Megan J. Waterman, Jeffery B. Birch, Oliver Schabenberger (2006): Linear Mixed Model Robust Regression. www.download $06 / 08 / 12$

[17]. NNPC (2012): "Corporate Safety Policy".

[18]. Pillai, Bagavathi, (2012): "Statistics, Theory and Practice"

[19]. Ronald, E.W, Raymond, H.M, Sharon. M., Keying ye (2001): "Probability and Statistic for ENGINEERS AND SCIENTISTS" $9^{\mathrm{TH}}$ Edition

[20]. Reason James (1990): Human Error, Cambridge University Press: ISBN 0-52- 131419-4

[21]. Siegel, (2002): Practical Business Statistics (Mc-Graw-Hill)

[22]. SCHAUM OUTLINES: (2004): "Probability and Statistics"

[23]. SHELDON M. ROSS (2001): “A first Course in Probability”, Eight Edition

[24]. Stranks (2007), "Human factors and behavioural safety".

[25]. Sunil, S. Rao (2004): "Industrial Safety, Health and Environment Management Systems".

[26]. Sunil, S. Rao (2004): "Management Approach for Ensuring Safety"

[27]. Yaya, (2006): Accident Prevention and Industrial Safety in KRPC". NNPC Chief Officers MDP Course 054 (Unpublished). PP. 8 